\title{
Simple equations for complex physiology: can we use VCO2 for calculating energy expenditure?
}

\author{
Pierre Singer ${ }^{1,2}$ \\ See related research by Stapel et al., http://www.ccforum.com/content/19/1/370
}

In a recent article, Stapel et al. [1] gave a practical and easy solution for the evaluation of energy expenditure in critically ill patients. Predictive equations are routinely used to determine energy needs and to guide the prescription of calories in critically ill patients [2]. However, their accuracy is very poor, resulting in both over- and underfeeding [3], and thus confounding the validity of many studies based on these equations. Indirect calorimetry remains the gold standard to determine calorie requirements, as well as to calculate energy expenditure (EE) from oxygen consumption (VO2), carbon dioxide production (VCO2) and nitrogen excretion (NM) measurements [4]. These devices are still seldom used since they may be expensive, require expertise and have several technical limitations [5]. Moreover, the most accurate device, the Deltatrac II (GE, Finland) is not widely available and other new devices have still to achieve its accuracy [6].

From the basic equation:

$$
\begin{aligned}
\mathrm{EE}(\mathrm{kcal})= & 3.581 \mathrm{VO} 2(\mathrm{~L})+1.448 \mathrm{VCO} 2(\mathrm{~L}) \\
& -1.773 \text { urinary nitrogen }(\mathrm{g})
\end{aligned}
$$

it is clear that the most important measurement for $\mathrm{EE}$ is $\mathrm{VO} 2$. A $10 \%$ error in $\mathrm{VO} 2$ causes a $7 \%$ error in $\mathrm{EE}$ while a $10 \%$ error in VCO2 causes a $3 \%$ error in EE [7]. Most devices are measuring $\mathrm{VO} 2$ and $\mathrm{VCO} 2$ or $\mathrm{VO} 2$ alone. EE derived from $\mathrm{VCO} 2$ alone was suggested already 25 years ago [8], using estimates of the energy equivalents of $\mathrm{CO}_{2}$ (energy expended $/ \mathrm{CO}_{2}$ produced; EeqCO2). Taking into account the variations in $\mathrm{CO}_{2}$ related to starvation or artificial enteral feeding, tracer techniques demonstrated that the calculation of resting

Correspondence: pierre.singer@gmail.com

${ }^{1}$ Critical Care Department, Institute for Nutrition Research, Rabin Medical

Center, Beilinson Hospital, Petah Tikva 49100, Israel

${ }^{2}$ Sackler School of Medicine, Tel Aviv University, Tel Aviv, Israel energy expenditure (REE) from $\mathrm{CO}_{2}$ production should not employ a universal value for $\mathrm{VCO} 2$. Nevertheless, measurement of $\mathrm{VCO} 2$ and the replacement of $\mathrm{VO} 2$ by $\mathrm{VCO} 2 / 0.84$ have been proposed to calculate EE [8]. This general value of 0.84 is the result of the arithmetic mean of the respiratory quotient $(\mathrm{RQ})$ of the three main macronutrients: $(1+0.809+0.707) / 3=0.84$. Since the measurement of $\mathrm{VCO} 2$ is available in many ventilator devices, it was suggested that this may be an easy and inexpensive way to calculate EE. Mehta et al. [9] used VCO2 alone in critically ill children to calculate EE and suggested that the REE may be obtained by measuring VCO2 through integrated devices in the ventilator or by a stand-alone monitor. The modified Weir equation (REE, $\mathrm{kcal} /$ day $=5.5 \times \mathrm{VCO} 2 \quad(\mathrm{~L} / \mathrm{min}) \times 1440$ using a fixed RQ of 0.89 ) was compared with predictive equations and found to be much more accurate [7]. However, there was an inherent inaccuracy due to the fixed RQ. When a RQ macro (based on the ratio of carbohydrate to fat in the diet) was used based on the ratio between carbohydrates to fat in the diet, a closer agreement was obtained between measured and REE derived from VCO2 alone, reaching a mean bias for agreement between measured REE and VCO2-derived REE of $-2.0 \%$, but with wide limits.

Sandra Stapel and colleagues [1] have proposed an even more sophisticated approach to achieve better accuracy using $\mathrm{VCO} 2$ alone in ventilated critically ill patients, extracting RQ from the nutrition regimen for each evaluation and not using a fixed value. When comparing this approach to mean 24 hour indirect calorimetry-based EE, bias was shown to be low, i.e., $141 \pm 153 \mathrm{kcal} /$ day and $7.7 \%$ of the gold standard. In addition, it was more precise than the more frequently used equations (limits of agreement -166 to $+447 \mathrm{kcal} /$ day). These results may encourage physicians who do not have access to direct 
calorimetry but have ventilators equipped with VCO2 measurement modified by an adapted $\mathrm{RQ}$, to derive $\mathrm{EE}$ from this measurement in order to more appropriately target the calorie prescription.

However, while the use of complicated mathematics resulted in good precision and low bias, the concept does not reflect the complexity of physiology in the critically ill patient. First the administered nutrients are only partially absorbed in these patients. Thus, small intestine glucose absorption is markedly impaired, independently of duodeno-cecal transit time [10] while lipid absorption is reduced by almost half when compared with healthy volunteers [11]. Secondly, endogenous glucose production is not depressed despite nutrition administration; adding a load of endogenous carbohydrates to the nutrient administration and autophagy provides endogenous lipids, carbohydrates and protein [12]. Third, secondary to stress, there is significant insulin resistance as well as obligatory lipolysis [13] and severe proteolysis which nutrients are unable to inhibit [14]. Finally, body substrate oxidation obtained by indirect calorimetry is far from the nutrient administration [15], making the correlation between the prescription and the respiratory quotient more difficult.

\section{Conclusion}

Stapel et al. based their theory on the fact that the absorbed macronutrients determine the $\mathrm{RQ}$, arguing that what is administered is utilized. While this approach may be preferred to predictive equations, it cannot reflect the complex physiologic changes seen in critically ill patients. Inaccuracies inherent in these types of calculations or measurements may explain why some interventional nutrition studies fail to achieve positive clinical outcomes.

\section{Abbreviations}

EE: energy expenditure; NM: nitrogen excretion; REE: resting energy expenditure; RQ: respiratory quotient; VCO2: carbon dioxide production; VO2: oxygen consumption.

\section{Competing interests}

PS has been receiving speaker fees from Cosmed and GE.

Published online: 21 March 2016

\section{References}

1. Stapel SN, de Grooth HJS, Alimohamad H, Elbers PW, Girbes AR, Weijs PJ, et al. Ventilator derived carbon-dioxide production to assess energy expenditure in critically ill patients: proof of concept. Crit Care. 2015;19:370.

2. Frankenfield D, Roth-Yousey L, Compher C. Comparison of predictive equations for resting metabolic rate in healthy nonobese and obese adults: a systematic review. J Am Diet Assoc. 2005;105:775-89.

3. Reid CL. Poor agreement between continuous measurements of energy expenditure and routinely used prediction equations in intensive care unit patients. Clin Nutr. 2007;26:649-57.

4. Singer $P$, Berger MM, Van den Berghe G, Biolo G, Calder P, Forbes A, et al. ESPEN Guidelines on Parenteral Nutrition: intensive care. Clin Nutr. 2009;28:387-400.
5. Compher C, Frankenfield D, Klein N, Roth YL. Best practice methods to apply to measurement of resting metabolic rate in adults: a systematic review. J Am Diet Assoc. 2006;106:881-903.

6. Graf S, Karsegard VL, Viatte V, Heidegger CP, Fleury Y, Pichard C, Genton L. Evaluation of three indirect calorimetry devices in mechanically ventilated patients: which device compares best with the Deltatrac $\|^{\oplus}$ ? A prospective observational study. Clin Nutr. 2015;34:60-5.

7. Bursztein $\mathrm{S}$. The theorical framework of indirect calorimetry and energy balance. In: Bursztein S, Elwyn DH, Askanazi J, Kinney JM, editors. Energy metabolism, indirect calorimetry and Nutrition: the theoretical framework. Baltimore: Williams and Wilkins; 1989. p. 27-84.

8. Elia M. Energy equivalents of $\mathrm{CO} 2$ and their importance in assessing energy expenditure when using tracer techniques. Am J Physiol. 1991;260:E75-88.

9. Mehta NM, Smallwood CD, Joosten KFM, Hulst JM, Tasker RC, Duggan CP. Accuracy of a simplified equation for energy expenditure based on bedside volumetric carbon dioxide elimination measurement-a two-center study. Clin Nutr. 2015;34:151-5.

10. Deane AM, Rayner CK, Keeshan A, Cvijanovic N, Marino Z, Nguyen NQ, et al. Effects of critical illness on intestinal glucose sensing, transporters, and absorption. Crit Care Med. 2014;42:57-65.

11. Abdelhamid YA, Cousins CE, Sim JA, Bellon MS, Nguyen NQ, Horowitz M, et al. Effect of critical illness on triglyceride absorption. J Parenter Enteral Nutr. 2014;39:966-72.

12. McClave SA, Weijs PJ. Preservation of autophagy should not direct nutritional therapy. Curr Opin Clin Nutr Metab Care. 2015;18:155-61.

13. Green P, Theilla M, Singer P. Lipid metabolism in critical illness. Curr Opin Clin Nutr Metab Care. 2015; in press.

14. Friedrich O, Reid MB. Vana den Berghe G, Vanhoerebeek I, Hermans G, Rich MM, Larsson L. The sick and the weak: neuropathies/myopathies in the critically ill. Physiol Rev. 2015;95:1025-109.

15. Tappy L, Chiolero R. Substrate utilization in sepsis and multiple organ failure. Crit Care Med. 2007;35:S531-4. 